\title{
Statistical avalanche-runout estimation for short slopes in Canada
}

\author{
Alan S.T. JONES, ${ }^{1}$ Bruae JAMIESON ${ }^{2}$ \\ ${ }^{1}$ P.O. Box 2845, Revelstoke, British Colombia V0E 2SO, Canada \\ E-mail: alanjones@netidea.com \\ ${ }^{2}$ Department of Civil Engineering, Department of Geology and Geophysics, University of Calgary, \\ 2500 University Drive NW, Calgary, Alberta T2N 1N4, Canada
}

\begin{abstract}
To develop avalanche runout models for short slopes, field measurements were made at 48 short-slope avalanche paths located in the Coast, Columbia and Rocky Mountains of western Canada, and at several paths in eastern Canada. Field studies included detailed topographic surveys and estimation of the extreme runout position in each path. A statistical runout model was developed using the runout ratio method, for which runout ratios from the four mountain ranges are well fit by an extreme-value type I (Gumbel) distribution when the $\beta$ point is defined at the uppermost point where the slope is $24^{\circ}$. A second model was developed by regressing the $\alpha$ angle for the extreme runout position on numerous terrain variables. This regression model uses three predictor variables that can be easily measured in the field or on topographic maps. Length-scale effects were noted in both models, but are more pronounced in the runout ratio model. A comparison of models developed using the two methods shows that the runout ratio model estimates more conservative (longer) runout distances than the regression model for most threshold probabilities. Data from 13 additional paths from Switzerland and Québec, Canada, are used to test the models.
\end{abstract}

\section{INTRODUCTION}

In Canada, avalanche hazards to structures, transportation corridors and residential areas are often mitigated by hazard or risk mapping, whereby the element at risk is situated in an area where avalanche return periods are acceptably long, and/or potential impact pressures are acceptably small (Jamieson and others, 2002, p. 14-17). When the risk from avalanches cannot be reduced to acceptable levels by location planning, mitigation measures such as avalanche control programs or defense structures may be applied.

The hazard- or risk-mapping process includes several steps in defining the avalanche problem and hazard areas. Some of the commonly applied methods include: terrain analysis of maps and aerial photographs; field studies of terrain; study of vegetation for signs of past avalanches; use of oral and written records of avalanches; weather and snow records; study of surficial materials; application of statistical models; and application of dynamic models (Jamieson and others, 2002, p. 9-10). While not all of these methods may be suitable for a particular problem, experts will typically combine several of these methods in their analysis, weighting the estimates in which they have greater confidence. Thus, application of statistical avalanche models is only one method used for some avalanche problems. This method is discussed in this paper for its applicability to a dataset consisting of avalanche paths with small vertical fall heights, hereafter called short slopes.

It has been found in practice that short slopes tend to run proportionately farther than larger slopes, and therefore the models developed for particular mountain ranges using statistical methods may not be applicable to short slopes (McClung and Lied, 1987; Nixon and McClung, 1993). This finding motivated our study of short slopes, in which data obtained from short avalanche paths in four Canadian mountain ranges (Fig. 1) are analyzed using the multiple regression method (e.g. Lied and Bakkehøi, 1980) and the runout ratio method (e.g. McClung and Mears, 1991). The results of analyses using these two different methods are compared and length-scale effects in the models are discussed. Finally, additional data from the Swiss Alps and the Chic Choc Range in Québec, Canada, are used to test the ability of the models to predict runout distances for paths not used to build the models.

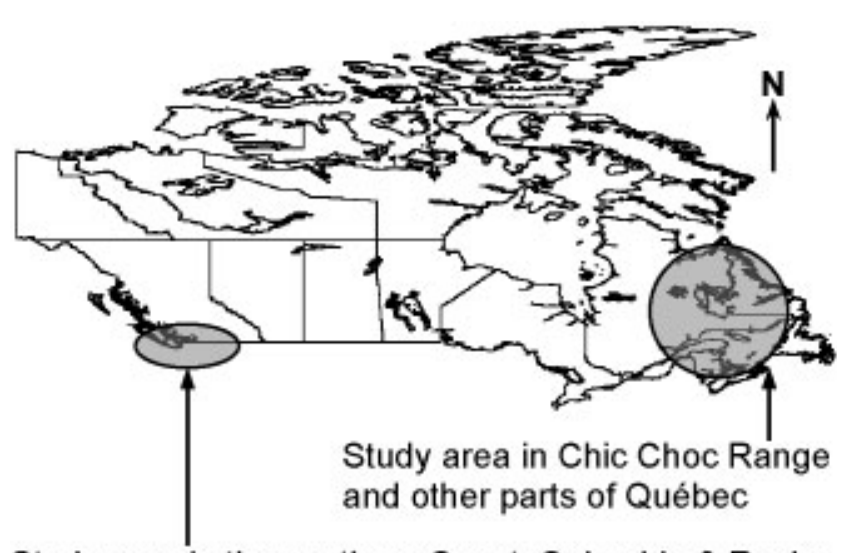

Study area in the southern Coast, Columbia \& Rocky Mountain Ranges of British Columbia and Alberta

Fig. 1. Location of study areas within Canada. 


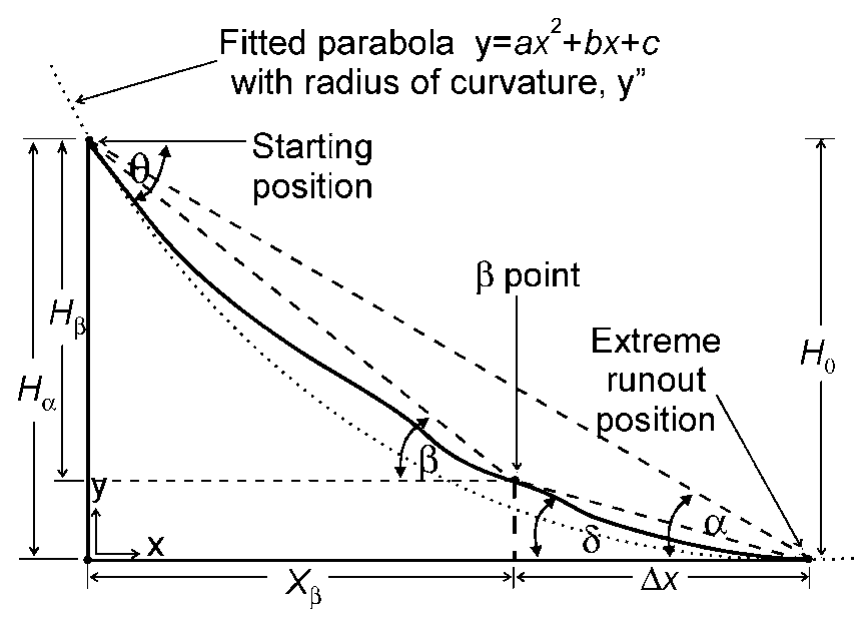

Fig. 2. Geometry of example avalanche path showing most terrain variables used in analyses. $x-y$ coordinate system is shown with origin at lower left of figure.

The preferred method for estimating avalanche runout distances in a path uses direct evidence from long-term observations of avalanches (McClung and Schaerer, 1993, p.115). In paths where little or no direct evidence of avalanche activity is available (e.g. paths with no historical records or no forest), runout models may be the preferred or only method available to estimate extreme runout distances for avalanches. One commonly used modelling technique is called the regression method, which is a statistical evaluation of known avalanche runouts in a mountain range, applied to a given avalanche path within the range. Bovis and Mears (1976) and Lied and Bakkehøi (1980) first used topographic terrain parameters to estimate runout distances for paths in the United States and Norway, respectively. Lied and Bakkehøi (1980) introduced the reference $\beta$ point in the runout zone from which to measure runout distances, which they defined as the position at which the slope angle first reaches $10^{\circ}$ when proceeding downslope from the starting position (Fig. 2). The corresponding $\beta$ angle is defined as the angle (measured from the horizontal) at the $\beta$ point to the starting position of the avalanche path. It is common to quantify extreme runout distances by using the $\alpha$ angle, defined as the angle (measured from the horizontal) at the extreme runout position observed in the field to the starting position of the avalanche path. The parameter $\alpha$ is similar to that used by Scheidegger (1973) to estimate the average friction coefficient for large landslides. For a group of avalanche paths in Norway, Lied and Toppe (1989) showed that $\beta$ was the only statistically significant predictor for $\alpha$, and developed regression equations relating the $\alpha$ angle to the $\beta$ angle. Similar expressions have been developed in Canada and the United States (McClung and others, 1989), Iceland (Jóhannesson, 1998), Austria (Lied and others, 1995) and Japan (Fujisawa and others, 1993).

A second statistical method used for estimating extreme runout distances is known as the runout ratio method. McClung and Mears (1991) found that the extreme runout positions for avalanche paths in a particular mountain range fit an extreme-value probability density function similar to that used for water discharge from floods. They defined the runout ratio, $\Delta x / X_{\beta}$, as the ratio of the horizontal distance from the $\beta$ point to the extreme runout position, $\Delta x$, to the horizontal reach from the starting position to the $\beta$ point, $X_{\beta}$ (Fig. 2). The runout ratio can take on positive or negative values, with a negative value indicating that the extreme runout position is located upslope of the defined $\beta$ point location (typically $10^{\circ}$ slope angle). The non-exceedance probability, $P$, is defined as the fraction of runout ratios in a particular mountain range that do not exceed a given ratio. Studies conducted for several ranges around the world (e.g. McClung and Mears, 1991; Nixon and McClung, 1993) have found significant statistical relationships between the runout ratio and the extreme-value non-exceedance probability (e.g. $R^{2}>0.95$ ) when applied to paths in a single mountain range (Mears, 1992, p.26). These results also show that each mountain range comprises a different population and thus each range should be analyzed separately.

In contrast to previous studies of slopes with a mean vertical fall height typically around $700 \mathrm{~m}$, McKittrick and Brown (1993) analyzed a dataset of mostly shorter slopes in southwest Montana, U.S.A., with a mean vertical fall height of $248 \mathrm{~m}$. They defined the $\beta$ point for their dataset as the location where the slope angle first decreases to $18^{\circ}$, rather than the conventional $10^{\circ}$. Although they offered no physical explanation of the improved fit of their data for a $\beta$ point at $18^{\circ}$, other studies have found that locking of particles in the avalanche flow may begin at slope angles of about $25^{\circ}$, and that large, dry avalanches may begin a decelerating phase at this slope angle (Gubler and others, 1986; McClung and Mears, 1995). Considering this another way, most avalanche dynamics models predict that the frontal velocity will increase then decrease, approximating a semi-ellipse along a parabolic path (e.g. Bartelt and Salm, 1998). Consequently, deceleration and locking should begin near the halfway point, measured horizontally. For an extreme avalanche running on a parabolic profile from a $38^{\circ}$ slope in the starting zone to a $5^{\circ}$ slope in the runout zone, deceleration should begin where the slope angle is approximately $21^{\circ}$. Based on these two observations, there may be a physical basis for using higher slope angles for defining the location of the $\beta$ point, particularly for shorter slopes in which the mass may not reach a high velocity (e.g. $>30 \mathrm{~m} \mathrm{~s}^{-1}$ ) before beginning to decelerate.

As early as 1987, McClung and Lied (1987) noted that their models likely did not apply well to paths with a vertical fall height of $<350 \mathrm{~m}$, and scale effects were noted for both their regression and runout ratio models. Mears (1989) and McClung and Mears (1991) noted the importance of lengthscale effects for data from the Colorado Rocky Mountains and the Sierra Nevada Range of California. Their findings and the work of Nixon and McClung (1993) suggest that the runout ratio decreases with increasing horizontal reach $\left(X_{\beta}\right)$, and illustrate the importance of scale effects in statistical runout modelling. These results support the hypothesis that extreme avalanches on smaller slopes run out proportionately farther than on taller slopes.

\section{METHODS}

Field studies included a detailed topographic survey and estimation of the extreme runout position for each path using either vegetative indicators or historical records of extreme avalanches. As with previous studies (e.g. McClung and Mears, 1991; McKittrick and Brown, 1993), the goal of the runout survey was to identify the location of the " 100 year" return period event, commonly referred to as the "extreme" 


\begin{tabular}{|c|c|c|c|c|c|c|}
\hline Variable & $n$ & Mean & Std dev. & Minimum & Median & Maximum \\
\hline Beta angle, $\beta\left(^{\circ}\right)\left(\right.$ defined at $\left.10^{\circ}\right)$ & 46 & 27.5 & 3.4 & 19.1 & 27.5 & 34.1 \\
\hline Vertical fall height to $\beta$ point, $H_{\beta}(\mathrm{m})$ & 46 & 180 & 107 & 27 & 183 & 512 \\
\hline Vertical fall height to $\alpha$ point, $H_{\alpha}(\mathrm{m})$ & 46 & 220 & 116 & 51 & 216 & 593 \\
\hline Horizontal reach to $\beta$ point, $X_{\beta}(\mathrm{m})$ & 46 & 276 & 153 & 52 & 267 & 643 \\
\hline Runout distance, $\Delta x(\mathrm{~m})$ & 46 & 162 & 129 & -109 & 123 & 568 \\
\hline Runout ratio, $\Delta x / X_{\beta}$ & 46 & 0.746 & 0.562 & -0.264 & 0.631 & 2.424 \\
\hline Delta angle, $\delta\left(^{\circ}\right)$ & 46 & 14.8 & 4.5 & 5.7 & 15.3 & 25.7 \\
\hline Alpha angle, $\alpha\left(^{\circ}\right)$ & 46 & 26.3 & 4.1 & 18.8 & 26.3 & 34.1 \\
\hline Vertical height to low point on parabola, $H_{0}(\mathrm{~m})$ & 46 & 239 & 127 & 51 & 232 & 584 \\
\hline Second derivative of the slope function, $y^{\prime \prime}\left(\mathrm{m}^{-1}\right)$ & 46 & 0.0023 & 0.0019 & 0.00065 & 0.0018 & 0.0085 \\
\hline Scale parameter for path profile, $H_{0} y^{\prime \prime}$ & 46 & 0.393 & 0.136 & 0.135 & 0.380 & 0.715 \\
\hline Starting-zone inclination $\theta\left(^{\circ}\right)$ & 46 & 38.2 & 5.0 & 27.5 & 38.0 & 47.5 \\
\hline Starting-zone aspect, Aspect $\left(^{\circ}\right)$ & 46 & 141 & 114 & 2 & 97 & 360 \\
\hline Runout-zone elevation, RZ Elev (m) & 46 & 1478 & 615 & 10 & 1641 & 2381 \\
\hline Surface roughness, SR $(\mathrm{m})$ & 46 & 0.5 & 0.4 & 0.1 & 0.3 & 1.5 \\
\hline Wind index, WI (ordinal data) & 46 & 3.5 & 1.2 & 2 & 4 & 5 \\
\hline Width of start zone, $W(\mathrm{~m})$ & 46 & 99 & 90 & 17 & 65 & 500 \\
\hline Terrain profile, TP (ordinal data) & 46 & 2.1 & 0.6 & 1 & 2 & 3 \\
\hline
\end{tabular}

runout position. However, the true return period for the interpreted extreme runout position likely represents return periods of 30-300 years, introducing unavoidable random variation in the data (McClung and Mears, 1991).

Paths were selected in the four mountain ranges based on several criteria, including: vertical fall height; reasonable access by vehicle and foot; well-defined path characteristics (e.g. starting and runout zones); well-defined extreme runout position; and no run-up on the opposite side of the valley or runout into a water body. Data were collected at 48 avalanche paths: 16 in the Coast Mountains, 10 in the Columbia Mountains, 15 in the Rockies and 7 paths in the Chic Choc Range or other parts of Québec. The Coast, Columbia and Rocky Mountain ranges are located in British Columbia and Alberta in western Canada, and the remaining paths are located in Québec, in the eastern part of Canada (Fig. 1). The paths vary from $48^{\circ} 47^{\prime}$ to $51^{\circ} 38^{\prime} \mathrm{N}$ latitude and from $65^{\circ} 55^{\prime}$ to $123^{\circ} 10^{\prime} \mathrm{W}$ longitude. Elevations of the starting zones of the paths range approximately from 85 to $2500 \mathrm{~m}$ above mean sea level. Thus, a geographically diverse sample set was obtained both in terms of latitude and longitude and in terms of elevation. See Jones (2002, p. 31-48) for a detailed discussion of field methods.

\section{DESGRIPTIVE STATISTICS}

The data used in this study consist of 19 terrain variables, for which the mean, standard deviation, median and range of the variables are shown on Table 1. Two of the 48 avalanche paths were rejected from the analyses for reasons discussed further below, and thus statistics for the remaining 46 paths are presented.

The total number of sites $(N)$ in this dataset, 48, is considered to be sufficiently large to analyze using both parametric and extreme-value statistical techniques. From the central limit theorem (Kennedy and Neville, 1986, p.117121), if $N \geq 30$, the normal approximation for the mean and variance of a response variable can be used with good precision even for an extreme-value distribution. However, the number of sites from the individual mountain ranges varies from 7 to 16 paths, which is well below this recommended sample size of 30 . Thus, only statistics for the combined ranges are presented.

Using the $\alpha$ and $\beta$ angles as defined previously (Fig. 2), we redefine the $\beta$ point as the position at which the slope angle first reaches $24^{\circ}$ when proceeding downslope from the starting zone. Jones (2002, p. 58-61) provides a statistical argument to support a $\beta$ point at $24^{\circ}$ for short slopes. We also present statistics for $\beta$ defined at $10^{\circ}$ for comparison to previous studies and testing in the multiple regression model.

The delta angle, $\delta$, is defined by sighting from the extreme runout position to the $\beta$ point, with the angle measured from the horizontal. This is a measure of the average slope angle in the runout zone.

The runout ratio relates the horizontal distances $\Delta x$ and $X_{\beta}$ to the reference slope angles $\alpha, \beta$ and $\delta$ (McClung and Mears, 1991)

$$
\frac{\Delta x}{X_{\beta}}=\frac{\tan \beta-\tan \alpha}{\tan \alpha-\tan \delta}
$$

The vertical distance, $H_{\beta}$, is measured from the starting position to the $\beta$ point, and $H_{\alpha}$ is the vertical distance from the starting position to the extreme runout position.

$H_{0}$ is defined as the vertical distance measured from the starting position to the lowest point on a polynomial parabolic curve $y=a x^{2}+b x+c$ fitted to the terrain profile of a path (Fig. 2), the location where the first derivative (slope of the polynomial curve), $y^{\prime}$, is zero. The second derivative of the polynomial curve, $y^{\prime \prime}$ (Fig. 2), has a value of $2 a$ and is the radius of curvature of the path profile (Lied and Bakkehøi, 1980). $H_{0} y^{\prime \prime}$ is the product of $H_{0}$ and $y^{\prime \prime}$, and serves as a dimensionless scale parameter (Lied and Bakkehøi, 1980).

The starting-zone inclination, $\theta$, starting-zone aspect and starting-zone elevation, SZ Elev, are average values measured in the starting zone. The runout-zone elevation, $\mathrm{RZ}$ Elev, is an average value measured in the runout zone. The surface roughness is an approximate measure of the height of irregularity in the ground surface, measured in metres. The wind index for each avalanche starting zone, 

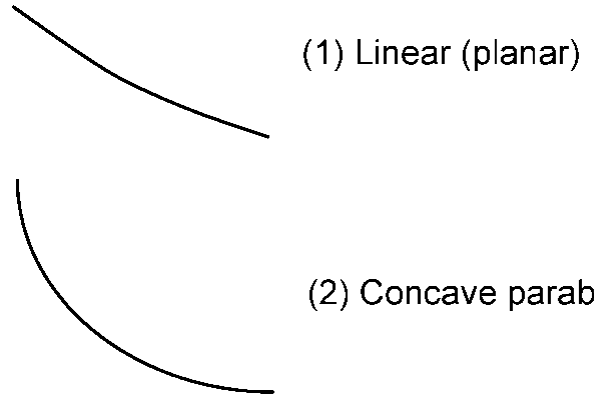

(2) Concave parabola

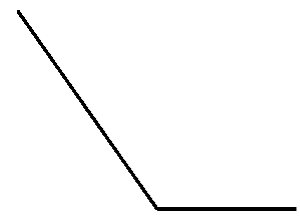

(3) Hockey-stick

Fig. 3. Examples of terrain profile types used for defining the TP variable.

WI, was assigned one of five ordinal values according to Schaerer (1977). The average width of the starting zone, $W$, was measured at the top of the starting zone.

The terrain profile variable, $\mathrm{TP}$, is related to the radius of curvature, $y^{\prime \prime}$, but accounts for the very abrupt change in curvature in hockey-stick profiles (Fig. 3). A value of 1 represents a slope with a nearly linear transition from the track to the runout zone; 2 represents a path with a concave parabolic shape and a relatively smooth transition from the track to the runout zone; and 3 represents a path with a hockeystick profile in which there is an abrupt transition from a relatively steep slope to a slope at or near $0^{\circ}$ in the runout zone (Martinelli, 1986). This type of profile may be commonly found where a steep slope meets a gently sloping or flat alluvial or glaciofluvial plain in a valley bottom.

The primary purpose of introducing the TP variable was to distinguish between hockey-stick and non-hockeystick profiles in the dataset. However, better discrimination between paths in the dataset was found, and better results were obtained, when a three-class TP variable was used. The three-class variable is a partially subjective categorical variable, but we believe that different experts would classify paths similarly, and thus TP is a reproducible variable. Paths with hockey-stick profiles were common in the dataset, with 10 of the 48 paths $(21 \%)$ classified as hockey sticks, $8(17 \%)$ classified as linear planar and $30(62 \%)$ classified as concave parabolas.

\section{ALPHA-REGRESSION MODEL}

Multiple regression was used to relate various independent predictor variables to the response variable, in this case the $\alpha$ angle used to define the extreme runout position. Fifteen predictor variables for $\alpha$ were chosen for the regression (Table 2).

Spearman rank correlations between the predictor variables and $\alpha$ are shown in Table 2, and significant variables $(p<0.05)$ are highlighted. Seven of the 14 variables are significant at the $5 \%$ level and these were used to build the regression model. Two other predictor variables $(\theta$ and TP) showed correlations of borderline significance with $\alpha$ $(0.05<p<0.1)$ and were also used in the regression. Backward-elimination multiple regression was used with
Table 2. Spearman rank correlations between the response variable, $\alpha$, and the predictor variables used to develop the alpha-regression model

\begin{tabular}{lccl}
\hline Variable & $N$ & $R$ & \multicolumn{1}{c}{$p^{1}$} \\
\hline$\beta\left(^{\circ}\right)\left(\right.$ defined at $\left.10^{\circ}\right)$ & $\mathbf{4 6}$ & $\mathbf{0 . 5 1}$ & $\mathbf{2 . 9} \times \mathbf{1 0}^{-\mathbf{4}}$ \\
$\beta\left(^{\circ}\right)\left(\right.$ defined at $\left.24^{\circ}\right)$ & $\mathbf{4 6}$ & $\mathbf{0 . 4 8}$ & $\mathbf{7 . 0} \times \mathbf{1 0}^{-\mathbf{4}}$ \\
$H_{\beta}(\mathrm{m})$ & $\mathbf{4 6}$ & $\mathbf{0 . 6 1}$ & $\mathbf{6 . 7} \times \mathbf{1 0}^{-\mathbf{6}}$ \\
$X_{\beta}(\mathrm{m})$ & $\mathbf{4 6}$ & $\mathbf{0 . 5 7}$ & $\mathbf{3 . 8} \times \mathbf{1 0}^{-\mathbf{5}}$ \\
$H_{0}(\mathrm{~m})$ & $\mathbf{4 6}$ & $\mathbf{0 . 5 4}$ & $\mathbf{1 . 0} \times \mathbf{1 0}^{-\mathbf{4}}$ \\
$y^{\prime \prime}\left(\mathrm{m}^{-1}\right)$ & 46 & -0.17 & 0.26 \\
$H_{0} y^{\prime \prime}$ & $\mathbf{4 6}$ & $\mathbf{0 . 5 4}$ & $\mathbf{1 . 1} \times \mathbf{1 0}^{-\mathbf{4}}$ \\
$\theta\left(^{\circ}\right)$ & 46 & 0.26 & 0.081 \\
Aspect $\left(^{\circ}\right)$ & 46 & -0.081 & 0.59 \\
$\mathrm{SZ} \mathrm{Elev}(\mathrm{m})$ & 46 & 0.086 & 0.57 \\
$\mathrm{RZ} \mathrm{Elev}(\mathrm{m})$ & 46 & 0.025 & 0.87 \\
SR $(\mathrm{m})$ & 46 & 0.067 & 0.66 \\
WI $($ ordinal data $)$ & 46 & -0.24 & 0.11 \\
$W(\mathrm{~m})$ & $\mathbf{4 6}$ & $-\mathbf{0 . 2 9}$ & $\mathbf{0 . 0 4 8}$ \\
TP $($ ordinal data) & 46 & -0.28 & 0.063 \\
& & & \\
\hline
\end{tabular}

${ }^{1}$ Rows for which $p \leq 0.05$ are marked in bold.

these nine predictor variables to obtain the best fit of the predicted values of $\alpha$ to the observed values.

Two significant outliers, excluded from Table 1, were identified and removed from the analyses because they did not reach a slope angle of $<28^{\circ}$ upslope of the interpreted location of the extreme runout position (continuously steep paths (McClung, 2001)), and a third was removed that had a much greater vertical fall height $\left(H_{\alpha}=593 \mathrm{~m}\right)$ than the other paths, leaving a subset $(n)$ of 45 paths for the regression. Variables were then systematically removed from the regression (backward elimination) when they were found to have a minimal effect on the model (i.e. variable $F$ values less than a specified threshold at each regression step). Using a threshold $F$ value at the $1 \%$ significance level, all variables but $H_{0} y^{\prime \prime}, H_{0}$, TP, $\beta$ (defined at $24^{\circ}$ ) and $X_{\beta}$ were eliminated from the regression. Additional analyses showed that $\beta$ and $X_{\beta}$ could also be removed from the regression with minimal effect on the results. The remaining three predictor variables in the regression equation were $H_{0} y^{\prime \prime}, H_{0}$ and TP. Removal of any of these three variables had a strong adverse effect on the fit, and thus the preferred regression is

$$
\alpha_{P}=21.11+22.41 H_{0} y^{\prime \prime}-3.02 \mathrm{TP}+0.01 H_{0}-C_{P} \mathrm{SE} \text {. }
$$

This model has an adjusted $R^{2}$ of 0.65 , a standard error of regression (SE) of $2.5^{\circ}$, a significance level of $10^{-4}$ and utilizes 45 of the avalanche paths in the dataset. The subscript $P$ is used to denote a runout estimate in probabilistic terms, in which it is assumed that runout distances expressed in terms of $\alpha_{P}$ are approximately normally distributed. A chosen exceedance value of $P(0<P<1)$ defines the number of $\alpha$ values for which $P \times 100 \%$ of the values in a normal distribution will not be less than the given value of $\alpha_{P}$. In order to avoid confusion with the similar (but opposite) term used for the runout ratio model, we use the term threshold probability to refer to the exceedance probability in the case of the alpha-regression model and non-exceedance probability in the case of the runout ratio model (McClung and Mears, 1991). The term $C_{P}$ provides an estimation interval for $\alpha_{P}$ and is used to estimate an individual value of $\alpha_{P}$ for a given threshold probability $P(0.5<P<1)$ (Walpole and Myers, 1985, p.371). McClung (2001) notes that for 
Table 3. Results of multiple regression for $\alpha$. Model-adjusted $R^{2}=0.65, n=45, \mathrm{SE}=2.5^{\circ}, p<10^{-4}$

\begin{tabular}{lcll}
\hline & Coefficient $\beta_{i}$ & Standard error of $\beta_{i}$ & $p$ \\
\hline Intercept & $21.11^{\circ}$ & $1.9^{\circ}$ & $5 \times 10^{-14}$ \\
$H_{0} y^{\prime \prime}$ & $22.41^{\circ}$ & $3.3^{\circ}$ & $3 \times 10^{-8}$ \\
$\mathrm{TP}$ & $-3.02^{\circ}$ & $0.76^{\circ}$ & $3 \times 10^{-4}$ \\
$H_{0}$ & $0.01^{\circ} \mathrm{m}^{-1}$ & $0.0040^{\circ} \mathrm{m}^{-1}$ & $3 \times 10^{-3}$ \\
\hline
\end{tabular}

$P>0.9$ and normally distributed data, $C_{P}$ reduces to the $z$ value of the normal distribution.

The three predictor variables chosen for this model are relatively simple topographic parameters that can be derived from a slope profile surveyed in the field or taken from a topographic map if a suitably scaled and detailed map is available. A summary of the regression is shown in Table 3.

Unlike previous studies (e.g. Bakkehøi and others, 1983; Nixon and McClung, 1993), we found that although $\beta$ is significantly correlated with $\alpha$ for this dataset when defined at either $10^{\circ}$ or $24^{\circ}(R=0.51$ and 0.48 , respectively, from Table 2), it does not provide a good single-variable regression for $\alpha$ (e.g. $R^{2}=0.26, \mathrm{SE}=3.6^{\circ}$ regressing $\alpha$ on $\beta$ defined at $10^{\circ}$ point). Four of the other predictor variables have higher significance levels with $\alpha$, and higher $F$ values in the regression. The final regression shown in Equation (2) is independent of where one defines the $\beta$ point, so this definition becomes unimportant once it is established that $\beta$ is not one of the top three predictors for multivariate regression for $\alpha$ for this dataset.

\section{RUNOUT RATIO METHOD}

McClung and Lied (1987) and McClung and Mears (1991) showed that a Gumbel distribution in the form

$$
P=\exp \left[-\exp \left(-\frac{\left(\Delta x / X_{\beta}\right)_{P}-u}{b}\right)\right]
$$

provides a good model for extreme avalanche runout distances. In this model, the runout ratio, $\Delta x / X_{\beta}$, is the continuous random variable, $u$ and $b$ are the location and scale parameters, respectively, and $P$ is the non-exceedance probability (threshold probability). A chosen value of $P$ represents the runout ratio for which $P \times 100 \%$ of the values in the dataset will not exceed that given value. Equation (3) can be rewritten as

$$
\left(\Delta x / X_{\beta}\right)_{P}=u-b \ln (-\ln (P)),
$$

where $-\ln (-\ln (P))$ is termed the reduced variate. By assigning appropriate non-exceedance values $P$ for each observed runout ratio in the dataset based on their rank order, it is possible to solve for $u$ and $b$ using least-squares linear regression techniques (McClung and Mears, 1991).

Based on the poor fit of the regression line to the data with the $\beta$ point defined at $10^{\circ}$, additional linear regressions were conducted by varying the $\beta$ point definition from $10^{\circ}$ through $27^{\circ}$. For our short-slope dataset, the best fit of the data to a Gumbel distribution occurs when the $\beta$ point is defined at $24^{\circ}$ (Jones, 2002, p. 58-61). Using this definition, $R^{2}$ is maximized at 0.98 and the standard error of regression, SE, is minimized at 0.080 (Fig. 4). The resulting regres-

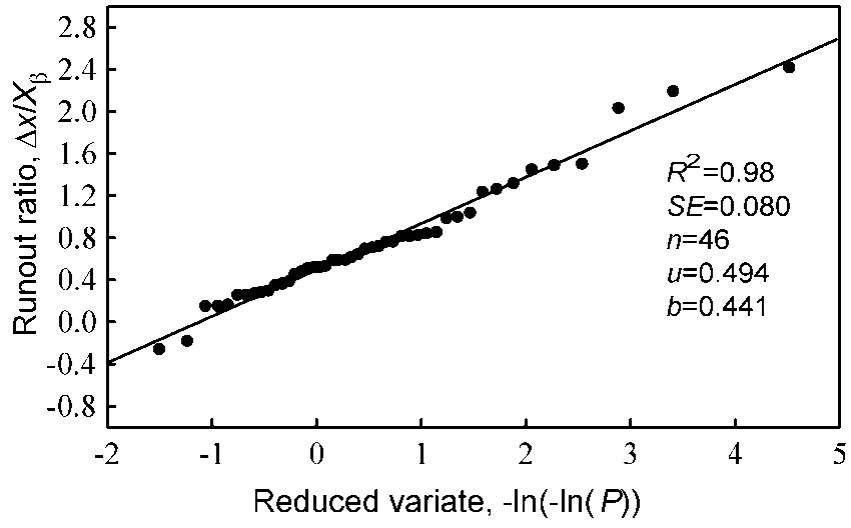

Fig. 4. Runout ratio fitted to an extreme-value (Gumbel) probability distribution for 46 avalanche paths in combined mountain ranges. $\beta$ point defined at $24^{\circ}$.

sion equation relating the runout ratio to the nonexceedance probability is

$$
\left(\Delta x / X_{\beta}\right)_{P}=0.494-0.441 \ln (-\ln (P)) .
$$

This regression uses data from 46 of the 48 avalanche paths in the dataset (minus the two outliers discussed in the previous section), combines paths from all four mountain ranges and is hereafter termed the four-range model. Similar analyses were done with individual mountain ranges, but the fit for individual ranges was either equal to or poorer than the fit obtained with the combined ranges (Jones, 2002, p. 62). Because the $\beta$ point was redefined in this study as the location where the slope first reaches $24^{\circ}$, there is little point in comparing the scale and location parameters from this model to parameters from previously developed models.

Two long-running avalanche paths (high runout ratios) were noted during the analyses, both of which had runout zones that were within partly confined stream channels. Channelization of avalanche flow in the runout zone may have contributed to the longer runout distances (McClung, 2001). These paths were included in the analyses since it is important the models are applicable for estimating extreme runout associated with long-running avalanche paths.

All previous work in the field of statistical avalanche-runout estimation has emphasized, as one of its underlying assumptions, that each region or mountain range constitutes a separate population of extreme runout distances, and that each region must be analyzed separately (Mears, 1992, p. 26). This analysis shows that a suitable model can be developed to represent short slopes in several mountain ranges in Canada, with all measured paths combined into one dataset. The four mountain ranges used in this study have very different climate characteristics, and represent all three of the generalized snow climates: maritime, continental and intermountain (McClung and Schaerer, 1993, p. 17-18).

\section{LENGTH-SGALE EFFEGTS}

As with previous studies (e.g. McClung and Mears, 1991), the model developed for the short-slope dataset exhibits a scale effect when the runout ratio is used to define runout distance. The coefficients of the Spearman rank correlations of the runout ratio, $\Delta x / X_{\beta}$, with either $H_{\beta}$ or $X_{\beta}$ are both $-0.55(n=46)$, which are highly significant $\left(p<10^{-4}\right)$. The negative correlations with the runout ratio show that 


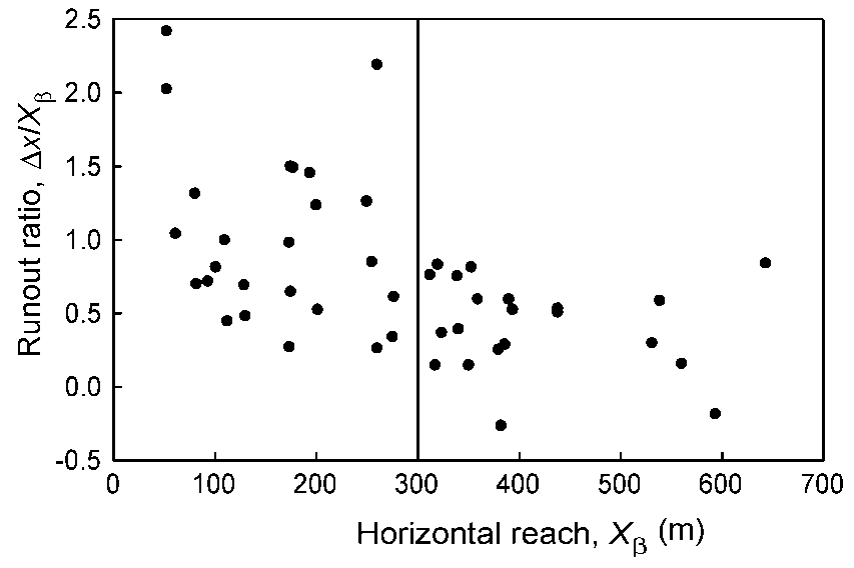

Fig. 5. Plot of the runout ratio vs the horizontal reach for the short-slope dataset, illustrating the length-scale effect in the runout ratio model.

proportionately longer runout distances are associated with shorter paths in the dataset, which is consistent with the findings of McClung and Mears (1991) and Nixon and McClung (1993). The relationship between the runout ratio and the horizontal reach is clearly illustrated in Figure 5, in which the runout ratio is seen as a decreasing function of increasing horizontal reach. The vertical line drawn at $X_{\beta}=300 \mathrm{~m}$ shows that there is a smaller range of runout ratios $\left(-0.5<\Delta x / X_{\beta}<1.0\right)$ associated with paths with horizontal reaches greater than approximately $300 \mathrm{~m}$ than with paths with horizontal reaches less than $300 \mathrm{~m}$. Thus, although some of the scale effect between larger slopes and short slopes is reduced with this model, there is still a scale effect for the runout ratio in the short-slope dataset.

Both McClung and Lied (1987) and McClung and Mears (1991) found that slopes with a vertical drop of $<350 \mathrm{~m}$ did not fit well into their dataset, and consequently trimmed these paths from their dataset. Additional analyses with our dataset indicate that the best-fit linear regression is found when the dataset is limited to slopes with a vertical fall height $\left(H_{\alpha}\right)$ of $<275 \mathrm{~m}$, measured from the starting position to the extreme runout position (Jones, 2002, p. 64). This may function as an approximate upper limit for which this "short-slope" model may be most applicable.

The scale effect for the alpha-regression model, although visually less pronounced than that observed with the runout ratio method, is still significant (Fig. 6). The Spearman rank correlation coefficients of $H_{\alpha}, H_{\beta}$ and $X_{\beta}$ with $\alpha$ are $0.44\left(p<10^{-2}\right), 0.61 \quad\left(p<10^{-5}\right)$ and 0.57 $\left(p<10^{-4}\right)$, respectively, indicating that decreasing $\alpha$ (increasing runout distance) is associated with decreasing vertical fall height and horizontal reach (smaller path size) for this regression model. Thus, scale effects within the dataset need to be considered when using models developed using both the runout ratio and alpha-regression methods.

For the Canadian short-slope dataset, the mean $\alpha$ is $26.3^{\circ}$ (standard deviation (SD) of $4.1^{\circ}, N=46$ ). McClung and Lied (1987) report a mean $\alpha$ of $31.1^{\circ}$ (SD of $6.4^{\circ}$, $N=212$ ) for a dataset from western Norway, and McClung and others (1989) report a mean $\alpha$ of $27.8^{\circ}$ (SD of $3.5^{\circ}, N=127$ ) for a dataset of taller Canadian paths. Conducting $t$ tests for the differences of the means, we find that the mean $\alpha$ for the short-slope dataset is significantly lower than mean values for both the Canadian taller slope $(t=2.2,70$ degrees of freedom (df), $p=0.02)$ and Norwegian $\left(t=6.4\right.$, df $\left.=180, p<10^{-6}\right)$ datasets.

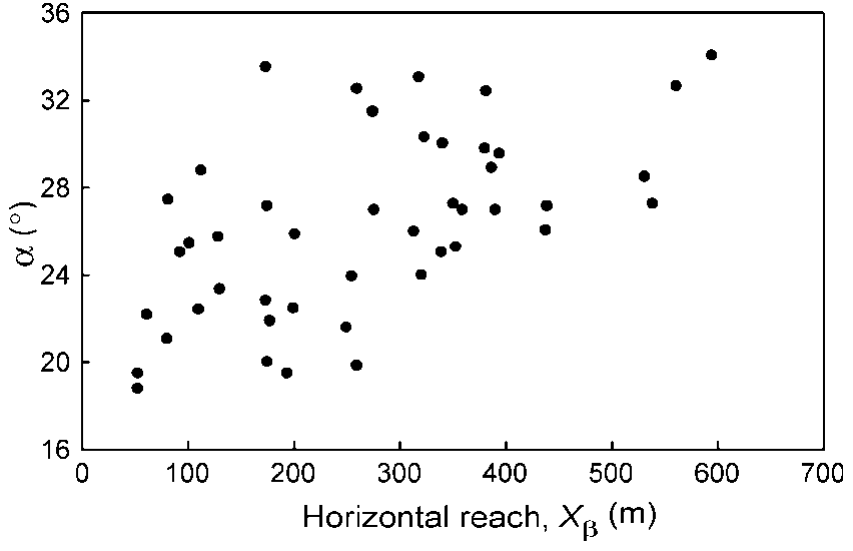

Fig. 6. Plot of observed $\alpha$ vs the horizontal reach for the shortslope dataset, illustrating the length-scale effect in the alpharegression model.

One important model limitation is that Equation (2) begins to fail for relatively larger paths with $H_{0}$ approximately greater than $500 \mathrm{~m}$. Large paths may tend to have higher values of $\alpha$ (e.g. $40^{\circ}$ maximum observed for the Canadian Purcell and Rocky Mountain ranges (McClung and others, 1989)), but values of $H_{0}$ approximately greater than $500 \mathrm{~m}$ result in $\alpha>45^{\circ}$, which are unreasonably high values of $\alpha$ for extreme avalanches, and much higher than those typically noted in the literature.

\section{GOMPARISON OF RUNOUT RATIO AND ALPHA-REGRESSION METHODS}

In the previous sections, avalanche runout models were developed using two different methods: the runout ratio (Equation (5)) and the alpha-regression method (Equation (2)). Both methods yield models that provide reasonably good fits to the sample of avalanche paths from this study. We follow the approach of Nixon and McClung (1993) for quantitatively comparing runout estimates by randomly selecting two avalanche paths from each mountain range, for a total of eight avalanche paths (Table 4). To compare the models in an unbiased manner, values for both the runout distance, $\Delta x_{P}$, and the equivalent $\alpha_{P}$ angle are presented. The results in Table 4 show that at higher values of $P(0.9$ and 0.99$)$ the runout ratio method estimates longer runout distances than the alpha-regression method for most paths, with the exception of the Brohm Ridge and Mont Jacques Cartier Saddle paths at $P=0.90$. This is consistent with the findings of Nixon and McClung (1993), and is explained by the fact that runout estimates based on the assumption that runout follows an extreme value distribution should be higher than estimates based on runout following a normal distribution. This result is most profound for the highest threshold probabilities analyzed $(P=0.99)$, where the runout ratio method estimates runout distances 1.5-4 times the distance estimated with the regression method. High threshold probabilities (e.g. $P=0.90$, $P=0.99)$ may be relevant for some engineering applications such as land-use planning.

At very high values of $P$ (e.g. $P \geq 0.90$ ), the runout ratio method estimates equivalent $\alpha$ values that appear to be unreasonably low (Table 4). A review of the literature (e.g. Lied and Bakkehøi, 1980; Martinelli, 1986; McClung and Mears, 1991; Nixon and McClung, 1993; Jóhannesson, 
Table 4. Comparison of runout distances and $\alpha$ angles for eight paths for the alpha-regression model $\alpha_{P}=21.11$ $+22.41 H_{0} y^{\prime \prime}-3.02 \mathrm{TP}+0.01 H_{0}-C_{P} \mathrm{SE}$ (Equation (2)) and the four-range model $\left(\Delta x / X_{P}\right)_{\beta}=0.494$ $-0.441 \ln (-\ln (P))$ (Equation (5))

\begin{tabular}{|c|c|c|c|c|c|c|c|c|}
\hline \multirow[t]{3}{*}{ Avalanche path } & \multirow[t]{3}{*}{$P$} & \multicolumn{2}{|c|}{ Regression model estimate } & \multicolumn{3}{|c|}{ Runout ratio model estimate } & \multicolumn{2}{|c|}{ Observed value } \\
\hline & & $\alpha_{P}$ & $\Delta x_{P}$ & $\alpha_{P}$ & $\Delta x_{P}$ & $\left(\Delta x / X_{\beta}\right)_{P}$ & $\alpha$ & $\Delta x$ \\
\hline & & $\circ$ & $\mathrm{m}$ & $\circ$ & $\mathrm{m}$ & & $\circ$ & $\mathrm{m}$ \\
\hline \multirow{4}{*}{ Wolverine Ridge } & 0.99 & 20.3 & 312 & 13.2 & 642 & 2.426 & \multirow{4}{*}{23.9} & \multirow{4}{*}{217} \\
\hline & 0.90 & 22.8 & 244 & 18.3 & 378 & 1.439 & & \\
\hline & 0.80 & 23.7 & 223 & 20.9 & 294 & 1.124 & & \\
\hline & 0.50 & 25.3 & 189 & 26.5 & 167 & 0.648 & & \\
\hline \multirow[t]{4}{*}{ Shark Mountain } & 0.99 & 20.0 & 370 & 11.5 & 957 & 2.426 & \multirow{4}{*}{29.8} & \multirow{4}{*}{96} \\
\hline & 0.90 & 22.5 & 279 & 16.1 & 564 & 1.439 & & \\
\hline & 0.80 & 23.5 & 248 & 18.4 & 439 & 1.124 & & \\
\hline & 0.50 & 25.0 & 205 & 23.5 & 249 & 0.648 & & \\
\hline \multirow[t]{4}{*}{ Apex Mountain east } & 0.99 & 23.2 & 281 & 12.8 & 815 & 2.426 & \multirow{4}{*}{30.3} & \multirow{4}{*}{115} \\
\hline & 0.90 & 25.8 & 212 & 17.9 & 480 & 1.439 & & \\
\hline & 0.80 & 26.7 & 191 & 20.4 & 373 & 1.124 & & \\
\hline & 0.50 & 28.3 & 158 & 25.8 & 212 & 0.648 & & \\
\hline \multirow[t]{4}{*}{ Schroeder Shoulder } & 0.99 & 21.3 & 293 & 12.0 & 801 & 2.426 & \multirow{4}{*}{30.1} & \multirow{4}{*}{48} \\
\hline & 0.90 & 23.9 & 219 & 16.7 & 472 & 1.439 & & \\
\hline & 0.80 & 24.9 & 195 & 19.2 & 367 & 1.124 & & \\
\hline & 0.50 & 26.5 & 160 & 24.4 & 208 & 0.648 & & \\
\hline \multirow[t]{4}{*}{ Brohm Ridge Col } & 0.99 & 16.1 & 441 & 14.7 & 504 & 2.426 & \multirow{4}{*}{22.5} & \multirow{4}{*}{247} \\
\hline & 0.90 & 18.7 & 347 & 20.4 & 279 & 1.439 & & \\
\hline & 0.80 & 19.7 & 317 & 23.3 & 231 & 1.124 & & \\
\hline & 0.50 & 21.2 & 277 & 29.2 & 131 & 0.648 & & \\
\hline \multirow[t]{4}{*}{ Cornice Ridge north } & 0.99 & 17.6 & 338 & 13.9 & 488 & 2.426 & \multirow{4}{*}{19.5} & \multirow{4}{*}{282} \\
\hline & 0.90 & 20.2 & 265 & 19.3 & 288 & 1.439 & & \\
\hline & 0.80 & 21.1 & 243 & 22.0 & 224 & 1.124 & & \\
\hline & 0.50 & 22.6 & 211 & 27.7 & 127 & 0.648 & & \\
\hline \multirow[t]{4}{*}{ Mont Jacques Cartier Saddle } & 0.99 & 17.2 & 472 & 14.3 & 628 & 2.426 & \multirow{4}{*}{21.6} & \multirow{4}{*}{314} \\
\hline & 0.90 & 19.7 & 374 & 19.8 & 370 & 1.439 & & \\
\hline & 0.80 & 20.7 & 341 & 22.6 & 288 & 1.124 & & \\
\hline & 0.50 & 22.2 & 298 & 28.4 & 163 & 0.648 & & \\
\hline \multirow[t]{4}{*}{ Mont de la Passe west } & 0.99 & 20.2 & 468 & 13.7 & 889 & 2.426 & & \\
\hline & 0.90 & 22.8 & 366 & 19.0 & 524 & 1.439 & & 287 \\
\hline & 0.80 & 23.8 & 332 & 21.7 & 407 & 1.124 & 20.3 & 287 \\
\hline & 0.50 & 25.3 & 286 & 27.4 & 231 & 0.648 & & \\
\hline
\end{tabular}

${ }^{1}$ Observed values of $\alpha$ and $\Delta x$ were estimated from vegetation damage during field studies or from historical records, corresponding to return periods of 30 to $>100$ years.

1998) shows that minimum observed $\alpha$ values are in the range $14-20^{\circ}$ for most studies of avalanche runout. Exceptionally low values are in the range $14-16^{\circ}$, with only one recorded $\alpha$ angle of $14^{\circ}$ in the Colorado Rocky Mountains (Martinelli, 1986). The lowest observed $\alpha$ angle from the short-slope dataset is $19^{\circ}$ (Table 1). Table 4 shows that for $P=0.99$ the runout ratio method estimates equivalent $\alpha_{P}$ angles of $12-15^{\circ}$, implying that this model may be overly conservative at high threshold probabilities. The alpharegression model estimates more realistic $\alpha_{P}$ angles of 16 $23^{\circ}$ for $P=0.99$.

\section{PROPOSED PHYSICAL EFFECTS OF VARIABLES IN MULTIPLE REGRESSION MODEL}

The three independent variables used in the regression model, $H_{0} y^{\prime \prime}, H_{0}$ and TP, are topographic parameters taken from the terrain profile for each path. While all three variables are statistically important parts of the regression model, the physical effect of each variable should be discussed to evaluate their individual contribution to the model.

The variable $H_{0} y^{\prime \prime}$ was found to be statistically significant in earlier studies (e.g. Lied and Bakkehøi, 1980;
McClung and Lied, 1987; Lied and others, 1995; Jóhannesson, 1998), but in all studies except for Lied and others (1995) was left out of the regression since it did not substantially improve the fit. In this study, $H_{0} y^{\prime \prime}$ is strongly and positively correlated with $\alpha$ (Table 2), which means that higher values of $H_{0} y^{\prime \prime}$ are associated with shorter runout distances. By assuming that the extreme runout position and the vertex of the fitted parabola for a path coincide, it is possible to show that $H_{0} y^{\prime \prime}$ is directly proportional to $\tan \alpha$. Thus, by geometry, $H_{0} y^{\prime \prime}$ is a promising predictor variable for $\alpha$, even without the tangent transformation and allowing for statistical scatter of the extreme runouts with respect to the vertex. This was shown to be true in this study.

$H_{0}$ is also strongly and positively correlated with $\alpha$, while $y^{\prime \prime}$ is not significantly correlated with $\alpha$ (Table 2). Interpretation of these correlations shows that paths with higher values of $y^{\prime \prime}$ (highly curved) and higher values of $H_{0}$ (taller slopes) are associated with higher values of $\alpha$, or relatively shorter runout distances. This agrees with the hypothesis of this study that shorter slopes have relatively longer runout distances than taller slopes in this dataset. In terms of avalanche dynamics, highly curved paths have 


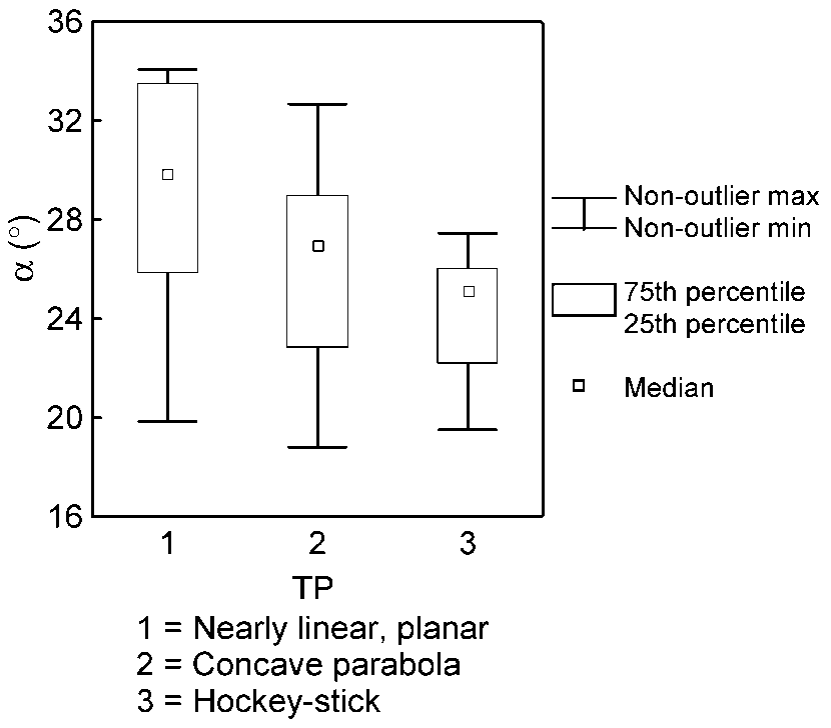

Fig. 7. Box-and-whisker plot showing the relationship between observed $\alpha$ and the terrain profile variable, TP. Maximum, minimum, 25th and 75 th percentiles and median are shown for each range of $\mathrm{TP}$.

higher energy losses associated with slope angles that decrease markedly down the path, and consequently reduced runout potential. The lowest amount of energy loss would be associated with a perfectly linear slope, for which $y^{\prime \prime}$ approaches 0 . While shorter slopes have relatively longer runout distances, as the strong positive correlation with $\alpha$ suggests, there is also a curvature effect in the model with respect to $y^{\prime \prime}$. Thus, $H_{0} y^{\prime \prime}$ may be a more important predictor variable for $\alpha$ than either $H_{0}$ or $y^{\prime \prime}$ alone.

The variable TP is negatively correlated with $\alpha$, but only at the $6 \%$ significance level. This variable is highly related to the radius of curvature, $y^{\prime \prime}$, but accounts for the very abrupt change in slope associated with hockey-stick profiles. Based on the negative correlation of TP with $\alpha$, paths with higher values of TP (i.e. hockey-stick profiles) are associated with lower values of $\alpha$, and consequently longer runout distances (Fig. 7). This finding agrees with Martinelli (1986) and McClung and Lied (1987) who observed unusually long runout distances associated with short-track, hockey-stick profile paths. One possible physical interpretation for this phenomenon is that fast-moving snow may become partly fluidized upon reaching an abrupt slope transition associated with paths with hockey-stick profiles (Martinelli, 1986; McClung and Lied, 1987; personal communication from K. Lied, 2002). Consequentially, extreme avalanches in these paths might flow greater distances because of entrained air and reduced frictional drag (Martinelli, 1986). Another explanation for this phenomenon is that there is a tendency for snow to be deposited at a sharp slope transition and for the remaining snow to override the material trapped in the transition area (McClung and Mears, 1995). The material trapped at the transition may serve to reduce frictional forces at the transition, resulting in relatively longer runout distances.

A third possible explanation is that the $\mathrm{TP}$ variable is simply compensating for the quadratic fit of the curves to the hockey-stick profiles. Both Lied and Bakkehøi (1980) and Martinelli (1986) fit their paths using parabolas, similar to this study. It may be the case in these paths that the $\beta$ points for the fitted curves should be located farther up-

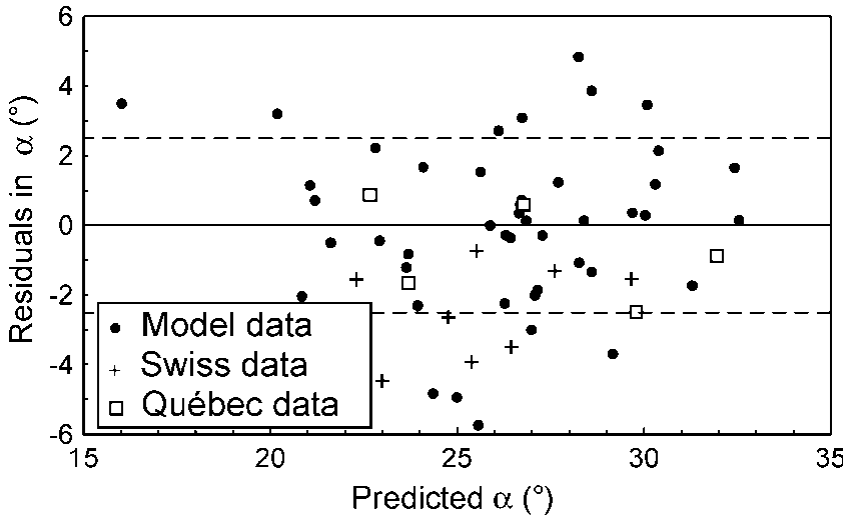

Fig. 8. Plot of residuals (observed minus predicted $\alpha$ ) vs predicted $\alpha$ using the alpha-regression model Equation (2)), with $P=0.50$. Dashed lines show the mean $\pm 1 \mathrm{SE}\left(2.5^{\circ}\right)$.

slope than the $\beta$ point at the transition of the hockey stick. Thus, when terrain parameters are taken from parabolas fitted to path profiles, avalanche paths with hockey-stick profiles run farther in relation to paths with other profiles. From a practical perspective, higher values of TP (i.e. $\mathrm{TP}=3$ for hockey sticks) are associated with lower values of $\alpha$, as shown by the negative contribution of TP to the alpha-regression model (Equation (2)) and shown graphically in Figure 7. Therefore, for conservative estimates of runout, one would prefer to choose higher values of TP in the model if unsure of which category of TP to apply to the path profile.

\section{TESTING THE SHORT-SLOPE RUNOUT MODELS}

In order to assess the usefulness of the runout models developed in this project, we analyzed 13 additional short-slope avalanche paths that were not included in the development of the models. Five of these paths are from the Chic Choc Mountain range in Québec, and thus are geographically within the area represented by this study. The other eight paths are from the Swiss Alps, thus representing a different sample in terms of geography and possibly climate. These additional paths have vertical fall heights of 59-320 $\mathrm{m}$ with a mean of $220 \mathrm{~m}$, which is the same mean vertical fall height $\left(H_{\alpha}\right)$ shown in Table 1.

A plot of residuals (observed - predicted) for $\alpha$ vs predicted $\alpha$ for the alpha-regression model shows that observed $\alpha$ angles are within one standard error of regression for all of the Québec paths and five of the eight Swiss paths (Fig. 8). Measured $\alpha$ angles are within two standard errors of regression for all of the paths. One notable trend in Figure 8 is that the model consistently underestimated runout for the Swiss paths, although only three of these estimates were more than one standard error of regression from the observed values. The most likely explanation for this trend is that these three Swiss data represent avalanches with longer return periods than the majority of paths in the short-slope dataset (personal communication from S. Margreth, 2002). On average, the Swiss paths may have longer return periods than the paths used to develop the Canadian regression model, which have return periods more likely in the range 30 to $>100$ years. This would explain why the model consistently underestimates runout for the Swiss data. Another possible reason is that the Swiss data represent a different 
statistical population than the Canadian dataset, and thus the regression model does not work well for predicting runout for paths outside of the four tested Canadian mountain ranges. Additional data from other mountain ranges would be useful for testing whether the applicability of these models is limited to the four Canadian mountain ranges.

When the four-range runout ratio model is used to predict runout for the 13 additional paths, a trend similar to that for the regression model can be observed (Fig. 9). The results shown in Figure 9 represent a non-exceedance probability of 0.5 , since this is a mean value for the paths in the dataset. The model provides good runout estimates for all of the Québec paths, within $15 \mathrm{~m}$ of the observed runout in three cases.

Similar to the alpha-regression model, the runout ratio model underestimates runout for three or four of the Swiss paths. However, the runout estimates for four of the eight paths were within $80 \mathrm{~m}$ of the observed runout distances, which are reasonably good estimates given the amount of uncertainty associated with avalanche runout modelling.

\section{SUMMARY}

In this paper, we presented and compared two methods for estimating runout distances for short-slope avalanche paths: one using the alpha-regression and the other using the runout ratio method. For both models, the reference $\beta$ point from which to measure runout distances was redefined for short slopes to be the position where the slope in the path first reaches $24^{\circ}$ proceeding downslope from the starting zone. This definition provided better fits of the short-slope data using both normal and extreme-value probability distribution functions. Two avalanche paths with very steep runout zones were removed from the analyses, leaving 46 paths available to develop the runout models.

A runout model was developed by regressing eight potential predictor variables on the $\alpha$ angle. This model uses three of these variables, $H_{0} y^{\prime \prime}$, TP and $H_{0}$, for the regression and provides a significant fit of the data to a normal distribution (adjusted $R^{2}=0.65, \mathrm{SE}=2.5^{\circ}$ ). Scale effects and the proposed physical explanations of the independent predictor variables on the alpha-regression model were discussed.

The runout ratio method was used to develop a model for estimating runout distances that fit a Gumbel extremevalue distribution function. The four-range model includes data from the four Canadian mountain ranges and is well fit by a Gumbel distribution $\left(R^{2}=0.98, \mathrm{SE}=0.080\right)$. Use of all four ranges in this analysis shows that there is little difference between mountain ranges in terms of runout distances for short slopes using the runout ratio method. Two long-running avalanche paths with runout zones within partly confined stream channels were noted in the analyses for the models. Channelization of the avalanche flow in the runout zone probably contributed to longer runout distances in these paths, and should be considered when estimating runouts.

A comparison of the two statistical methods shows that the runout ratio method estimates more conservative (longer) runout distances than the alpha-regression method for most threshold probabilities. This effect is very pronounced for the higher-threshold probabilities (e.g. $P=0.99$ ), where the runout ratio method estimates runout distances up to four times that estimated by the alpha-regression method.

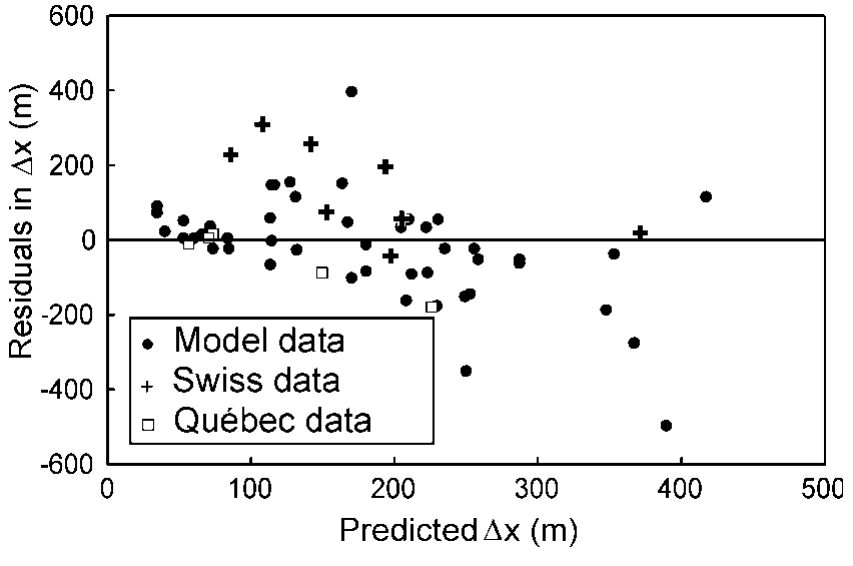

\begin{abstract}
Fig. 9. Plot of residuals (observed minus predicted $\Delta x$ ) vs predicted $\Delta x$ using the four-range runout ratio model (Equation (5)) with $P=0.50$.
\end{abstract}

When terrain parameters are taken from parabolas fitted to path profiles, avalanches in paths with hockey-stick profiles tend to run farther in relation to paths with parabolic or almost linear profiles. This has important implications for estimating runout distances for short slopes, particularly when applied to land-use planning.

The models were tested using data from 13 additional short-slope avalanche paths, eight from the Swiss Alps and five from the Chic Choc range in Québec. Both models provide good runout estimates for the five Québec paths. Both models tend to underestimate runout distances for the Swiss paths when compared to the observed runout. However, both models provide reasonable estimates of runout for four of the eight Swiss paths, showing that these models may be used with caution for other ranges, taking into account the uncertainty associated with the models (i.e. using appropriate threshold probabilities). Additional studies would be required to assess the suitability of the models for individual mountain ranges not represented in this study.

This study included 48 avalanche paths, which was sufficient to build models for combined mountain ranges but was not sufficient data for properly assessing each range individually. Thus, a larger dataset could be developed that includes more paths in the individual ranges. There also may be important climatic variations within these ranges that influence runout distances. Further studies could look into specific climate variables (e.g. 30 year maximum water equivalent of snowfall) and assess their effect on runout distances.

\section{ACKNOWLEDGEMENTS}

For financial support while the first author was a graduate student at the University of Calgary we are grateful to the British Columbia Ministry of Transportation, the Association of Professional Engineers, Geologists and Geophysicists of Alberta, the Department of Civil Engineering at the University of Calgary, and to Canada's Natural Sciences and Engineering Research Council. For their contributions to this project including advice, guidance, resources and identifying field sites we thank: J. Bennetto, H. Bluer, G. Bonwick, F. Bouchart, D. Clapp, M. Deschenes, C. Diezfelbinger, D. Germain, J. Goodrich, P. Hein, B. Hétu, P. Jordan, P. Kimmel, K. Lied, D. McClung, L. McKittrick, B. McLeod, B. McMahon, M. Maes, L. Nkemdirim, P. Schaerer, R. Schroeder, R. Siggers, 
D. Skjonsberg, C. Stethem and D. Wilson. For field assistance we are grateful to K. Paulig and G. Johnson. For providing additional data for testing the models we thank D. Germain, B. Hétu and S. Margreth. Finally, we would like to thank the two anonymous reviewers and the editor, F. Sandersen, for their helpful comments and suggestions that greatly improved this paper.

\section{REFERENCES}

Bakkehøi, S., U. Domaas and K. Lied. 1983. Calculation of snow avalanche runout distance. Ann. Glaciol., 4, 24-29.

Bartelt, P. and B. Salm. 1998. A short comparison between Voellmy-fluid and Criminale-Ericksen-Filby-fluid dense snow avalanche models. In Hestnes, E., ed. 25 Years of Snow Avalanche Research, Voss 12-16 May 1998. Proceedings. Oslo, Norwegian Geotechnical Institute, 65-69. (NGI Publication 203.)

Bovis, M. J. and A. I. Mears. 1976. Statistical prediction of snow avalanche runout from terrain variables in Colorado. Arct. Alp. Res., 8(1), 115-120.

Fujisawa, K., R. Tsunaki and I. Kamiishi. 1993. Estimating snow avalanche runout distances from topographic data. Ann. Glaciol., 18, 239-244.

Gubler, H., M. Hiller, G. Klausegger and U. Suter. 1986. Messungen an Fliesslawinen. Zwischenbericht 1986. Eidg. Inst. Schnee-und Lawinenforsch. Mitt., 41.

Jamieson, J. B., C. J. Stethem, P. A. Schaerer and D. M. McClung, eds. 2002. Land managers guide to snow avalanche hazards in Canada. Revelstoke, B.C., Canadian Avalanche Association.

Jóhannesson, T. 1998. A topographic model for Icelandic avalanches. Reykjavík, Vedurstofa Íslands. (Icelandic Meteorological Report VI-G98003UR03.)

Jones, A. S. T. 2002. Avalanche runout prediction for short slopes. (M.Sc. thesis, University of Calgary, Department of Civil Engineering.)

Kennedy, J. B. and A. M. Neville. 1986. Basic statistical methods for engineers and scientists. Third edition. New York, Harper and Row Publishers Inc.
Lied, K. and S. Bakkehøi. 1980. Empirical calculations of snow-avalanche runout distance based on topographic parameters. F. Glaciol., 26(94), 165-177.

Lied, K. and R. Toppe. 1989. Calculation of maximum snow-avalanche runout distance by use of digital terrain models. Ann. Glaciol., 13, 164-169.

Lied, K., C. Weiler, S. Bakkehøi and J. Hopf. 1995. Calculation methods for avalanche run-out distance for the Austrian Alps. Oslo, Norges Geotekniske Institutt. (Report 581240-1.)

Martinelli, M., Jr. 1986. A test of the avalanche runout equations developed by the Norwegian Geotechnical Institute. Cold Reg. Sci. Technol., 13(1), 19-33.

McClung, D. M. 2001. Extreme avalanche run-out: a comparison of empirical models. Can. Geotech. F., 38(6), 1254-1265.

McClung, D. M. and K. Lied. 1987. Statistical and geometrical definition of snow avalanche runout. Cold Reg. Sci. Technol., 13(2), 107-119.

McClung, D. M. and A. I. Mears. 1991. Extreme value prediction of snow avalanche runout. Cold Reg. Sci. Technol., 19(2), 163-175.

McClung, D. M. and A. I. Mears. 1995. Dry-flowing avalanche run-up and run-out. f. Glaciol., 41 (138), 359-372.

McClung, D. M. and P. A. Schaerer. 1993. The avalanche handbook. Seattle, WA, The Mountaineers.

McClung, D. M., A. I. Mears and P. A. Schaerer. 1989. Extreme avalanche run-out: data from four mountain ranges. Ann. Glaciol., 13, 180-184.

McKittrick, L. R. and R. L. Brown. 1993. A statistical model for maximum avalanche run-out distance in southwest Montana. Ann. Glaciol., 18, 295-299.

Mears, A. I. 1989. Regional comparisons of avalanche-profile and runout data. Arct. Alp. Res. 21(3), 283-287.

Mears, A. I. 1992. Snow-avalanche hazard analysis for land-use planning and engineering. Colorado Geol. Surv. Bull. 49.

Nixon, D. J. and D. M. McClung. 1993. Snow avalanche runout from two Canadian mountain ranges. Ann. Glaciol., 18, 1-6.

Schaerer, P. 1977. Analysis of snow avalanche terrain. Can. Geotech. F., 14(3), 281-287.

Scheidegger, A. E. 1973. On the prediction of the reach and velocity of catastrophic landslides. Rock Mechanics, 5(4), 231-236.

Walpole, R. E. and R. H. Myers. 1985. Probability and statistics for engineers and scientists. Third edition. New York, Macmillan Publishing Co. Ltd. 